\title{
Regional Agricultural Production Efficiency Disparity and Efficiency Decomposition of China's Pastoral Area
}

\author{
Yanbing Jia \\ College of Economy \& Management, Sichuan Agriculture University \\ No.46 Xin Kang Street, Yaan 625014, Sichuan, China \\ Tel: 86-138-8244-5698Ｅ-mai:someone191954@126.com \\ Wenxiu Zhang (Corresponding author) \\ College of Economy \& Management, Sichuan Agriculture University \\ No.46 Xin Kang Street, Yaan 625014, Sichuan, China \\ Tel: 86-133-0816-1528Ｅ-mail: cndzwx@163.com \\ Peng Tang \\ College of Economy \& Management, Sichuan Agriculture University \\ No.46 Xin Kang Street, Yaan 625014, Sichuan, China \\ Tel: 86-138-8244-6674 E-mai:tp2han@163.com
}

Received: September 20, $2010 \quad$ Accepted: October 9, 2010 doi:10.5539/jas.v3n2p183

This paper is funded by project"Research on Problems and Countermeasures of New Countryside Construction in China's Western Minority Area” (07XJY021) sponsored by the National Philophy and Social Fund of 2007.

\begin{abstract}
Since the western development, pastoral agriculture production of China has made considerable progress. Based on the $C^{2} \mathrm{R}$ model and super-efficiency DEA model in this paper, the time variance and provincial diversity of the China's pastoral areas and agricultural production efficiency among provinces from 2000 to 2008 were investigated empirically. The results indicated that: (1)since the western development, the efficiency of agricultural production in both nation's pastoral areas and all provincial pastoral areas had grown evidently, except that in Tibet autonomous region; (2)according to the efficiency decomposition, the variance in efficiency of agricultural productivity was mainly caused by technical efficiency. And the improvements of scale efficiency are relatively limited; (3) according to the spatial structure distribution of time changes, the differences of efficiency of agricultural production in each province were very obvious.
\end{abstract}

Keywords: Efficiency of agricultural production, DEA analysis, Regional differences, Efficiency decomposition

\section{Introduction}

The discussion of the theory and calculation of the productivity, started from the research on American economy by Solow (1956). Then the total factor productivity (TFP) had growth in some countries and regions effectively. Agricultural productivity growth is the basis of social economic growth. The research on agricultural productivity has always been a focus by development economists and agricultural economists (Jiyu Jiang \& Jing $\mathrm{Li}, 2005)$. For China, how to achieve sustainable development of agriculture has been a problem of economic development. There are two mainly methods to increase agricultural productivity, one is increasing factor inputs; the other is boosting agricultural production efficiency. Lack of agricultural production resources leads us not to improve agricultural productivity by increasing factor inputs, but only by the latter one.

Sustained growth of agricultural productivity, not only raises the income level of farmers, but also offers the labor force needed by non-agricultural industry. However, the labor force reallocation from low-effective agriculture to high-effective non-agricultural industries had been a major headspring of the economic growth in 
China (Yongtai Hu, 1998, p31-39). Many scholars has already researched a lot (McMillan, Whalley \& Zhu, 1989, p781-807; Yifu Lin, 1992, p34-51; Wen, 1993, p1-41). Generally speaking, China's agricultural productivity was stagnation before 1978. And it declined about 25\% in 1952-1977 (Wen, 1993, p1-41). Even more seriously, almost in all provinces, agricultural productivity had gotten a negative growth during 1970-1978. In addition, some researches on the household contract responsibility system since 1979 agree its benefits, which mainly attributes to system vicissitude (McMillan, Whalley \& Zhu, 1989, p781-807; Yifu Lin, 1992, p34-51; Wen, 1993, p1-41). It is worth mentioning that in the late 20th century the systemic study on China's agricultural productivity was by Lambert \& Parker (1998, p378-392). They discovered, the periods of the most significant growth of agricultural productivity were the beginning of rural reform and the acceleration of market economy reform. And it emerged huge differences among all provinces. Hsu, Yu \& Chang (2003, p27-30), Nin et al. (2003, p928-942), Jones \& Arnade (2003, p1-5) also reached an analogous conclusion.

Meanwhile, productivity measurement methods were innovative. Mahadevan (2003) according to whether use the parameter estimation, measured the methods of TFP growth including parameter estimation and non-parameter estimation. Parameter estimation defines the form of production function. It estimates the coefficients of all parameters by measuring regression, then measures TFP growth. In addition to whether to adopt the conditions of frontier production function, the methods can be classified as non-frontier non-parametric estimation and non-frontier parameter estimation, parameter estimation front, non-parameter estimation. Most scholars in China firstly studied on general scientific and technological progress of agricultural problems in the area of agricultural production efficiency (Yifu Lin, 1992, p34-51; Xigang Zhu, 1997; Heping Jiang \& Jicai Su, 2001). They measured the scientific and technological progress of agricultural economic growth by different ways, which laid the foundation for later researches on agricultural productivity. Zhao Hongbin (2004, p91-110), on the basis of the studies of Heping Jiang \& Jicai Su (2001), added dummy variables (two special periods before and after 1978) and constraint condition. This study found, China's technological progress efficiency in agriculture was lower than that in economics. Moreover, in empirical research, Xiaoyan Han \& Yinli Zhai (2005, p52-57), in the context of comparing agricultural productivity of each province, checked up its convergence and factors of $\beta$ convergence by Barrow Regression. In addition, some scholars (Jiyu Jiang, Jing Li \& Lingjie Meng, 2005, p113-118; Weiping Chen, 2006, p18-23), comparative statically and dynamically analyzed on the agricultural production efficiency in different regions by Malmquist productivity index. In addition, Daniel (2009) also carried out further expansion. They firstly used data envelopment analysis method to estimate the efficiency of agricultural production index, then used censored regression model and semi-parametric self-guided method to explain the differences in productivity index.

Current literature and its prospects have covered on all aspects of agricultural production efficiency. But so many problems still need to explain. From the existing foreign literature, most of the time range of academic research focused on China's reform and opening up to the middle of 1990s. They paid attention to agricultural productivity which combined with agricultural production system and market economy reform. However, Chinese scholars studied later. And most of their researches used traditional parameters analysis. On the one hand, many studies based on the behavior optimization of producers production for the conditions of neo-classical theory. The solution in production efficiency was like that in technological progress, which could not distinguish the role of enhancing efficiency. On the other hand, the explanatory indeterminacy of agricultural growth origin of the nation and especial each province was due to different estimated methods and human factors, which caused differences in their findings. From discussing the efficiency of agricultural production, more researches emphasized on level of the nation. In despite of even the research on regional differences, the country was divided into eastern, central and western regions to be explained. Existing research studies are mainly on rural areas, but lack of systematic research on the pastoral areas. In order to avoid the defects of parameters estimated analysis, this paper based on authoritative data, combined with a specific institutional context and the geographical environment, adopted Data Envelopment Analysis(DEA), and quantitatively investigated the variation regulation of agricultural production efficiency of China's pastoral areas from 2000 to 2008. On the basis of its decomposition, we further analyzed on regional differences in agricultural productivity.

\section{Estimation framework}

DEA analysis belongs to a new interdisciplinary area of operations research, management science and mathematical economics. It is an approval that well-known economist Charnes \& Cooper (1978, p429-444) based on relative efficiency concept and developed similar evaluation of multiple input and multiple output relative efficiency of decision making unit evaluation method. The basic idea adopted input and output values to form an effective production frontier and used the observed sample of data, to appraise decision-making unit or handle other multi-objective decision making. DEA model has many forms. It represents a $\mathrm{C}^{2} \mathrm{R}$ model, $\mathrm{BC}^{2}$ 
model, FG model and the ST model. In this paper, we reference $C^{2} R$ model and super-efficiency DEA model to measure the efficiency of agricultural production in pastoral areas of China.

$$
\begin{aligned}
& \min \left[\theta-\varepsilon\left(\sum_{i=1}^{s} S_{i}^{+}+\sum_{r=1}^{m} S_{r}^{-}\right)\right] \\
& \text {s.t. }\left\{\begin{array}{l}
\sum_{j=1}^{n} \lambda_{j} X_{j}+S^{-}=\theta X_{0} \\
\sum_{j=1}^{n} \lambda_{j} Y_{j}-S^{+}=Y_{0} \\
\lambda_{j} \geq 0, \quad j=1,2, \ldots, \quad n \\
S^{+} \geq 0, \quad S^{-} \geq 0
\end{array}\right.
\end{aligned}
$$

Model(1) The DEA of $\mathrm{C}^{2} \mathrm{R}$

$$
\begin{gathered}
\min \left[\quad \theta-\varepsilon\left(\sum_{i=1}^{s} S_{i}^{+}+\sum_{r=1}^{m} S_{r}^{-}\right)\right] \\
\text {s.t. }\left\{\begin{array}{l}
\sum_{\substack{j=1 \\
j \neq \gamma}}^{n} \lambda_{j} X_{j}+S^{-}=\theta X_{\gamma} \\
\sum_{\substack{j=1 \\
j \neq \gamma}}^{n} \lambda_{j} Y_{j}-S^{+}=Y_{\gamma} \\
\lambda_{j} \geq 0, \quad j=1,2, \ldots, \quad n \\
S^{+} \geq 0, \quad S^{-} \geq 0
\end{array}\right.
\end{gathered}
$$

Model(2) The DEA of super-efficiency

Here, $X_{j}, Y_{j}$ are aggregation of the input and output element of decision aking unit(DMU). $\theta$ means a radial effective optimization or a distance from DMU to effective front surface, specifically expresses overall efficiency of agricultural production in a particular year here. It is more effective if it is closer to $1 ; \varepsilon$ shows non-Archimedean infinitesimal, and is a positive number less than any number and greater than 0 . In this paper, it is equal to $10^{-7} ; \lambda_{j}$ is a assembled proportion of decision making unit $j$ which relates to DMU and reconstruct an efficient DMU aggregation; $S^{+}$and $S$ - are slack variable for invalid $\mathrm{DMU}_{j}$ extending from horizontal or vertical direction to achieve efficient frontier.

If the optimal solution of model(1) are $\theta^{0}, \lambda^{0}, S^{+0}$ and $S^{0}$, according to DEA theorem, if $\theta^{0}=1$ and $\sum_{\mathrm{i}=1}^{\mathrm{s}} S_{i}^{+}+\sum_{r=1}^{m} \mathrm{~S}_{\mathrm{r}}^{-}=0, \mathrm{DMU}_{j 0}$ is effective for the DEA. It said the investment is neither fully equal to geometric compression, nor there is a excessive nvestment or eficiency output; if $\theta^{0}=1$ and $\sum_{\mathrm{i}=1}^{\mathrm{s}} S_{i}^{+}+\sum_{r=1}^{m} \mathrm{~S}_{\mathrm{r}}^{-}>0, \mathrm{DMU}_{j 0}$ is weak efficient for DEA. There emerge excess input and deficiency output; if $\theta^{0}<1, \mathrm{DMU}_{j 0}$ is not effective for DEA. That means under the best condition of the input and output, input would be compressed as the proportion as $\theta^{0}$ times, which can also reach the current level of output; under $\kappa=\frac{\sum \lambda_{\mathrm{j}}^{0}}{\theta}$ assumption, if $k<1$, scale profit increases progressively; if $k=1$, it is constant; if $k>1$, it diminishes progressively.

The mathematical notations and economic connotation in Model(2) are same with the former. The only difference is, when decision making unit $\gamma$ appraises efficiency, its input and output are substituted for those of the others. However, it excludes the decision making unit $\gamma$, but model 1. An effective decision-making unit can make its input increase as the proportion, its efficiency maintain, and the input growth ratio exceed the value of its efficiency evaluation.

\section{Region}

In China, the distribution of pastoral areas and semi-agricultural semi-pastoral areas is consistent with the distribution of natural grassland area. That mainly distributes in the frontier grasslands, where is in the frontier grassland areas of "western Songnen Plains-middle and upper reaches of Liao River-Yinshan Mountains-eastern margin of the Ordos Plateau-Qilian Mountains-the north and the west of the Tibetan Plateau". Geographical area not only involved in six major pastoral areas (Figure 1 and Figure 2): Inner Mongolia autonomous region, Xinjiang autonomous region, Tibet autonomous region, Tsinghai province, Sichuan province and Gansu province, but also included Ningxia autonomous region, Heilongjiang province, Jilin province, Liaoning province, Hebei province, Shanxi province. In 1978, there were 187 pastoral and semi-pastoral counties (banners). After several adjustments, in 2008, there were 120 pastoral counties (banners) and 144 semi-pastoral counties (banners), and total land area was 4.2662 million $\mathrm{hm}^{2}$, which accounted for $44.4 \%$ of land area in China. The population in those areas inhabiting by the Mongolian, Tibetan, Kazakh, Tajik, Yugur, Ewenki, Kirgiz, Daur (more than 40 minorities) was almost 40 million. More than $50 \%$ population was agricultural and animal husbandry. Agriculture played a leading role in the national economy.

\section{Data}

Based on the research objectives and considered the representation and availability of data, this paper established DEA relative efficiency evaluation $C^{2} R$ model and the super-efficiency DEA model by using 10 decision-making 
units DMU, which were composed of each agricultural production input and output data from 2000-2008 in six major pastoral provinces of China.

\subsection{Input indicator}

Conducting research in agricultural production activities, the most important input indicators were labor and capital. And in view of the agriculture was restricted by means of production, production technology and other factors, in addition to the inputs of capital and labor factors into account, the need to consider other indicators. Therefore, this paper selected five indicators to represent each kind of resource input which was required by agricultural production run, which were labor of farming, forestry, animal husbandry and fishery, the total motive power of farm machinery, chemical fertilizer rate (pure amount of discount), the effective irrigated area, crop acreage.

\subsection{Output indicator}

The main objective of agricultural production is the production of agricultural products and increasing their income, taking into account a wide range of agricultural products, can not simply add up all the numbers. Therefore, this paper selected for three indicators to represent the productive capacity of agricultural, output value of farming, forestry, animal husbandry and fishery, the per capita net income of agriculture, food production.

\section{Results}

\subsection{Comprehensive efficiency analysis}

According to previously described methods, using nonlinear programming software Lingo8.0, importing agricultural production input and output data into the model(1), which was in pastoral areas provinces from 2000 to 2008, under the assumption of constant returns to scale (CRS), from the investment point of view, calculated the evaluation results $\theta_{1}$ of overall agricultural production efficiency for each year. To comparing effective decision-making units $\left(\theta_{1}=1\right)$, by using model (2), then calculated $\theta_{2}$, and accordingly sort the results in Table 1 .

Since entering the 21 st century, to the Chinese government, how to solve the three rura issue was a top priority task of all, the state further promoted the western economic and social development by implementing the western development strategy. The results in Table 1 showed that during this period, agricultural production efficiency, there has been more substantial growth, annual growth of $1.8 \%$. From all provinces of view, different degrees of growth, the fastest-growing of agricultural production efficiency is Tsinghai province, the average annual growth of 5.3\%; average annual growth rate of agricultural production efficiency in Inner Mongolia autonomous region, Xinjiang autonomous region, Sichuan province, Gansu province were $2.8 \%, 1.2 \%, 2.3 \%$ and $3.4 \%$; change is least obvious in Tibet autonomous region, agricultural production efficiency average was only $0.04 \%$. In addition, the effectiveness of view from the DEA, the overall performance of agricultural production efficiency in pastoral areas of China is not very good, and the DEA only in 2008 was effective, it means that compared to other years, only this year, the proportion of agricultural input and output in different combinations has achieved the best results, and there was not other ways to improve the agricultural outputs. The remaining years were the non-effective DEA efficient units $\left(\theta_{1}<1\right)$, showed that, in recent years, agricultural production resources were not being fully utilized, not to maximize agricultural output. Sub-regional to see, spatial distribution showed marked regional differences, in addition to DEA effective year in Tibet was more than $85 \%$, the other provinces of the DEA effective year were less than $40 \%$. This also showed, the agricultural production efficiency of pastoral areas was still much room for improvement.

From Table.1, by observation of super-efficiency value and ranking can easily found from 2000 to 2008 , either in the whole or a sub-provincial pastoral areas, the development trend of agricultural output capacity presented fluctuation and pick up. From the specific situation of pastoral provinces, in 2005, Tibet autonomous region had the least comprehensive efficiency, only 0.9877 , and in 2008, strongest in agricultural output capacity, reached 1.1341. The possible causes of pastoral agricultural production efficiency changed as that, the natural conditions had a great influence on agricultural production, but the pastoral areas were mostly distributed in Northwest China and Southwest China, poor natural conditions, natural endowments affected the agricultural production inputs and food production. In addition, non-effective decision-making unit in 2001-2003 was primarily due to the national removal the protection of grain price, grain price reduction. the enthusiasm of the farmers was hurt, and then they continued to cut food, agricultural social and economic benefits were affected, and ultimately reflected in lower levels of agricultural production efficiency. The agricultural production efficiency began to rise in 2004, mainly due to the substantive support to agriculture from the state. Another possible reason was that during the evaluation of pastoral areas, the agricultural production resources were not fully utilized, or put 
excessive, resulting in waste of resources.

\subsection{Decomposition analysis of the efficiency}

According to DEA decomposition principle, drawing lessons from Fare, Grosskopf \& Lovell (1994), under the assumption of variable returns to scale (VRS), separated scale efficiency $(S E)$ variability index, $\operatorname{SEC}\left(x_{t+1}, y_{t+1} ; x_{t}\right.$, $\left.y_{t}\right)$, and pure technical efficiency $(P T E)$ variability index, PTEC $\left(x_{t+1}, y_{t+1} ; x_{t}, y_{t}\right)$ from production frontier. Specific decomposition formula is:

$$
\begin{aligned}
\theta\left(x^{t+1}, y^{t+1} ; x^{t}, y^{t}\right) & =\frac{\theta_{0}^{t+1}\left(x^{t+1}, y^{t+1} \mid C, S\right)}{\theta_{0}^{t}\left(x^{t}, y^{t} \mid C, S\right)} \\
& =\frac{\theta_{0}^{t+1}\left(x^{t+1}, y^{t+1} \mid C, S\right) / \theta_{0}^{t+1}\left(x^{t+1}, y^{t+1} \mid V, S\right)}{\theta_{0}^{t}\left(x^{t}, y^{t} \mid C, S\right) / \theta_{0}^{t}\left(x^{t}, y^{t} \mid V, S\right)} \cdot \frac{\theta_{0}^{t+1}\left(x^{t+1}, y^{t+1} \mid V, S\right)}{\theta_{0}^{t}\left(x^{t}, y^{t} \mid V, S\right)} \\
& =\frac{S E_{0}^{t+1}\left(x^{t+1}, y^{t+1} \mid C, S\right)}{S E_{0}^{t}\left(x^{t}, y^{t} \mid C, S\right)} \cdot \frac{\theta_{0}^{t+1}\left(x^{t+1}, y^{t+1} \mid V, S\right)}{\theta_{0}^{t}\left(x^{t}, y^{t} \mid V, S\right)} \\
& =\operatorname{SEC}\left(x^{t+1}, y^{t+1} ; x^{t}, y^{t}\right) \cdot \operatorname{PTEC} \quad\left(x^{t+1}, y^{t+1} ; x^{t}, y^{t}\right)
\end{aligned}
$$

Here, $C$ means constant returns to scale, $V$ means variable returns to scale, $S$ means under the defined output, each required input elements can alternated freely.

Analysis of technical efficiency. The results in Table.2 showed that the overall performance of agricultural technical efficiency in pastoral areas was good, with the exception of 2006 was only 0.9952 . Excepted 2001 and 2007, the technical efficiency index of each decision-making unit was higher than the scale efficiency index, and the scale index was less than 1 . With the exception of 2008, the composite index was less than 1 . Thereby, the results showed that, to a very great extent, the benefits from improving the technical efficiency were offset by the relative low level of scale efficiency. The low scale efficiency showed that, under certain technical level, the input of agricultural production resources did not reach optimum size. This was closely related to the natural conditions in pastoral areas, a vast region, together with the household contract responsibility system, a family was managed, and that was difficult to expand agricultural production internal returns. While the farm household management was the subject, it was difficult to generate the internal returns to scale by concentration expanding the land. In addition, from the various provinces, during the evaluation of pastoral areas, the technical efficiency in Inner Mongolia autonomous region, Xinjiang autonomous region, Tibet autonomous region, Tsinghai province, Gansu province and other provinces were 1, indicating that the agricultural production technical conditions in these years had reached the best condition. In 2001 of Sichuan province, the technology efficiency was only $0.9983(P T E C<1)$, showed that the agricultural production technical conditions in this year had not reached the best condition, some technical level had not reached the general requirements, but also higher than the value of the scale index.

Analysis of scale efficiency and returns. Calculating the ratio of integrated Efficiency and technical efficiency, that was the scale efficiency. While scale efficiency more approached 1, the more close to the optimum size. Table. 1 and Table. 2 showed that, DEA effective years were in the period of constant returns to scale, which is also the effective size. If these years expanded in a certain proportion, and then its output will increase by the same proportion, that means those years of agricultural inputs were reasonable, had reached the maximum returns to scale. On the whole, except in 2008, the agricultural production efficiency in China's pastoral areas in the year of increasing returns to scale, that was, in these years, increasing investment can still played a role in agriculture economic growth. Sub-provinces of view, Inner Mongolia autonomous region, except in 2007 and 2008, the other years were increasing returns to scale; Xinjiang autonomous region only in 2000, 2001 and 2004, these three years were increasing returns to scale; only in 2005, Tibet autonomous region was increasing returns to scale, other years are in the stage of constant returns to scale; in addition to 2001,2007 and 2008, Tsinghai province were increasing returns to scale; in addition to 2004, 2007 and 2008, Gansu province were increasing returns to scale; it is noteworthy that Sichuan in 2001, technical efficiency and scale efficiency were both need to improve, except in 2004 and 2008, the other years were increasing returns to scale.

\section{Discussions}

As we all know, evaluation and analysis of agricultural production efficiency was a complex issue, based on data envelopment analysis, this paper evaluated and analyzed agricultural production efficiency in China's pastoral areas from 2000 to 2008. whether from the method or from the sample point, it was just regarded as an attempt to more clearly reflect the actual situation in China's pastoral areas, and provide some reference for the departments of agricultural production and management in ethnic regions, in improving the structure of 
agricultural inputs and outputs, and ultimately improving the overall efficiency of agricultural production. The results show that, since the development of the West, whether from the whole, or sub-provinces of the Chinese agricultural production efficiency growth in pastoral areas are more obvious, made important contributions to the whole agricultural growth. Furthermore, the growth of current agricultural production efficiency in China's major pastoral areas mainly depended on the increase of technical efficiency rather than scale efficiency improvements. Moreover, the evolution in space, the provincial agricultural productivity growth and constitute existed a significant difference.

From the evaluation of the agricultural production efficiency, combination of the time changes and spatial distribution, the ideal future agriculture model of sustainable development should improve the agricultural frontier of technological progress, technical efficiency and scale efficiency side by side, and promote agricultural growth in pastoral areas together, and this was the specific way to realized the future agricultural intensive growth. Specifically, was to further improve and perfect the agricultural technology extension system, in particular, to strengthen allocation of the primary agricultural technology service station and staffing. From analysis of decomposition, we can learn that the DEA non-efficiency of agricultural production efficiency in China's pastoral areas, were mainly due to the non-efficiency of scale efficiency, and the other, the actual view from the pastoral areas, most of pastoral or agricultural production were mainly small farmers economy, which farmers were the operating entity, the scale of agricultural operations was too small, thus restricting the formation of scale and increase efficiency. Therefore, we should actively promote the regionalization, appropriate scale, professional management of the farming and breeding industry, and achieve economies of scale in agriculture.

\section{Reference}

Chames, A., Cooper \& W. W. Rhodese. (1978). Measuring the efficiency of decision making units European. Journal of Operational Research, No.2(61). p429-444.

Chen, Weiping. (2006). Productivity growth, technical progress and efficiency change in Chinese agriculture: 1990-2003. China Rural Survey. No.1.p18-23.

Daniel, C. Monchuk. (2009). The non-efficiency analysis of agricultural productivity in China. World Economic Papers, No.2. p47-56.

Fare, R., Grosskopf, S. \& Lovell, C. (1994).Production Frontier. Cambridge: Cambridge University Press.

Hsu, S-H, M. M. Yu \& C. C. Chang. (2003). An analysis of total factor productivity growth in China's agricultural sector. Canada: Prepared for American Agricultural Economics Association Annual Meting, p27-30.

Han, Xiaoyan \& Zhai, Yinli. (2005). A Study on regional difference and convergence of agricultural productivity in China. Jouranl of Agricultural Economics, No.6. p52-57.

$\mathrm{Hu}$, Yongtai. (1998). The primary role in reallocation of labor from the agricultural sector and totalfactor productivity in China. Journal of Economic Research, No.3. p31-39.

Jiang, Heping \& Su Jicai. (2001). Calculation and analysis of contribution rate of agricultural science and technology progress in China. Jouranl of Agricultural Economics, No.5. p12-17.

Jiang, Jiyu, Li, Jing \& Meng, Lingjie. (2005). The growth tendency of agricultural productivity in China:1978-2002. Journal of Nanjing Agriculture University, No.28(3). p113-118.

Jones, K. \& C. Amade. (2003). A joint live stock-crop multi-factor relative productivity approach. Alabama: Prepared for Southem Agricultural Economics Association Annual Meeting, No.3. p1-5.

Lambert, D. \& E. Parker. (1998). Productivity in Chinese provincial agriculture. Journal of Agricultural Economics, No.49.p378-392.

Lin, Yifu. (1992). Rura1 reforms and agricultural growth in China. American Economic Review, No.82.p34-51.

Mahadevan, R. (2002). To measure or not to measure total factor productivity growth. Oxford Development Studies.

McMillan, J., J. Whalley \& L. Zhu. (1989). The impact of China's economic reforms on agricultural productivity growth. Journal of Political Economy, No.197. p781-807.

Nin, A., C. Amdt, T. W. Herel \& P. V. Preckel. (2003). Bridging the gap between partial and total productivity measures using direction distance functions. American Journal Agricultural Economic, No.85. p928-942.

Solow, Robert, M. (1956). A contribution to the theory of economic growth. Quarterly Journal of Economics, 
No.70. p65-94.

Wen, G. J. (1993). Total factor productivity change in China's farming sector: 1952-1989. Economic Development and Cultural Change, No.42. p1-41.

Zhu, Xigang. (1997).Analysis of contribution rate of agricultural science and technology progress in China. Beijing: China Agricultural Press.

Zhao, Hongbing. (2004). A study on the technological change of Chinese primary industry since reform in 1978. Journal of Finance and Economics, No. 30(12). p91-110.

Table 1. The evaluation results of agricultural production efficiency in China's pastoral areas 2000-2008

\begin{tabular}{|c|c|c|c|c|c|c|c|c|c|c|}
\hline \multicolumn{2}{|l|}{ Region } & 2000 & 2001 & 2002 & 2003 & 2004 & 2005 & 2006 & 2007 & 2008 \\
\hline \multirow{2}{*}{ Inner Mongolia } & $\theta_{1}$ & 0.9809 & 0.9040 & 0.9674 & 0.8990 & 0.9417 & 0.9809 & 0.9802 & 1 & 1 \\
\hline & $\theta_{2}$ & 0.9809 & 0.9040 & 0.9674 & 0.8990 & 0.9417 & 0.9809 & 0.9802 & 1.0682 & 1.2224 \\
\hline \multirow{2}{*}{ Xinjiang } & $\theta_{1}$ & 0.9956 & 0.9691 & 1 & 1 & 0.9830 & 1 & 1 & 1 & 1 \\
\hline & $\theta_{2}$ & 0.9956 & 0.9691 & 1.0537 & 1.0150 & 0.9830 & 1.0282 & 1.0348 & 1.0296 & 1.0970 \\
\hline \multirow{2}{*}{ Tibet } & $\theta_{1}$ & 1 & 1 & 1 & 1 & 1 & 0.9877 & 1 & 1 & 1 \\
\hline & $\theta_{2}$ & 1.1301 & 1.0360 & 1.0062 & 1.0360 & 1.0156 & 0.9877 & 1.1340 & 1.1284 & 1.1341 \\
\hline \multirow{2}{*}{ Tsinghai } & $\theta_{1}$ & 0.8447 & 1 & 0.9272 & 0.9177 & 0.9499 & 0.9519 & 0.9164 & 1 & 1 \\
\hline & $\theta_{2}$ & 0.8447 & 1.0333 & 0.9272 & 0.9177 & 0.9499 & 0.9519 & 0.9164 & 1.2252 & 1.2727 \\
\hline \multirow{2}{*}{ Sichuan } & $\theta_{1}$ & 0.9775 & 0.9003 & 0.9416 & 0.9439 & 0.9782 & 1 & 0.9049 & 0.9691 & 1 \\
\hline & $\theta_{2}$ & 0.9775 & 0.9003 & 0.9416 & 0.9439 & 0.9782 & 1.0081 & 0.9049 & 0.9691 & 1.1724 \\
\hline \multirow{2}{*}{ Gansu } & $\theta_{1}$ & 0.9184 & 0.9466 & 0.9746 & 0.9847 & 0.9916 & 1 & 0.9866 & 1 & 1 \\
\hline & $\theta_{2}$ & 0.9184 & 0.9466 & 0.9746 & 0.9847 & 0.9916 & 1.0214 & 0.9866 & 1.0570 & 1.1999 \\
\hline \multirow{2}{*}{ China's pastoral areas } & $\theta_{1}$ & 0.9594 & 0.9114 & 0.9643 & 0.9471 & 0.9668 & 0.9915 & 0.9452 & 0.9849 & 1 \\
\hline & $\theta_{2}$ & 0.9594 & 0.9114 & 0.9643 & 0.9471 & 0.9668 & 0.9915 & 0.9452 & 0.9849 & 1.1707 \\
\hline
\end{tabular}

Table 2. Decomposition of agricultural production efficiency in China's pastoral areas 2000-2008

\begin{tabular}{|c|c|c|c|c|c|c|c|c|c|c|}
\hline \multicolumn{2}{|l|}{ Region } & 2000 & 2001 & 2002 & 2003 & 2004 & 2005 & 2006 & 2007 & 2008 \\
\hline \multirow{3}{*}{ Inner Mongolia } & PTEC & 1 & 1 & 1 & 1 & 1 & 1 & 1 & 1 & 1 \\
\hline & SEC & 0.9809 & 0.9040 & 0.9674 & 0.8990 & 0.9417 & 0.9809 & 0.9802 & 1 & 1 \\
\hline & $k$ & 0.7970 & 0.8825 & 0.9514 & 0.9065 & 0.9200 & 0.9571 & 0.9531 & 1 & 1 \\
\hline \multirow{3}{*}{ Xinjiang } & PTEC & 1 & 1 & 1 & 1 & 1 & 1 & 1 & 1 & 1 \\
\hline & SEC & 0.9956 & 0.9691 & 1 & 1 & 0.9830 & 1 & 1 & 1 & 1 \\
\hline & $k$ & 0.9572 & 0.9698 & 1 & 1 & 0.9354 & 1 & 1 & 1 & 1 \\
\hline \multirow{3}{*}{ Tibet } & PTEC & 1 & 1 & 1 & 1 & 1 & 1 & 1 & 1 & 1 \\
\hline & SEC & 1 & 1 & 1 & 1 & 1 & 0.9877 & 1 & 1 & 1 \\
\hline & $k$ & 1 & 1 & 1 & 1 & 1 & 0.9936 & 1 & 1 & 1 \\
\hline \multirow{3}{*}{ Tsinghai } & PTEC & 1 & 1 & 1 & 1 & 1 & 1 & 1 & 1 & 1 \\
\hline & SEC & 0.8447 & 1 & 0.9272 & 0.9177 & 0.9499 & 0.9519 & 0.9164 & 1 & 1 \\
\hline & $k$ & 0.9490 & 1 & 0.9432 & 0.8976 & 0.8849 & 0.9227 & 0.9394 & 1 & 1 \\
\hline \multirow{3}{*}{ Sichuan } & PTEC & 1 & 0.9983 & 1 & 1 & 1 & 1 & 1 & 1 & 1 \\
\hline & SEC & 0.9775 & 0.9018 & 0.9416 & 0.9439 & 0.9782 & 1 & 0.9049 & 0.9691 & 1 \\
\hline & $k$ & 0.9870 & 0.9395 & 0.9686 & 0.9534 & 0.9662 & 1 & 0.9859 & 0.9795 & 1 \\
\hline \multirow{3}{*}{ Gansu } & PTEC & 1 & 1 & 1 & 1 & 1 & 1 & 1 & 1 & 1 \\
\hline & SEC & 0.9184 & 0.9466 & 0.9746 & 0.9847 & 0.9916 & 1 & 0.9866 & 1 & 1 \\
\hline & $k$ & 0.9343 & 0.9593 & 0.9664 & 0.9599 & 0.9720 & 1 & 0.9836 & 1 & 1 \\
\hline \multirow{3}{*}{ China's pastoral areas } & PTEC & 1 & 1 & 1 & 1 & 1 & 1 & 0.9952 & 1 & 1 \\
\hline & SEC & 0.9594 & 0.9114 & 0.9643 & 0.9471 & 0.9668 & 0.9915 & 0.9498 & 0.9849 & 1 \\
\hline & $k$ & 0.9583 & 0.9395 & 0.9560 & 0.9362 & 0.9502 & 0.9667 & 0.9624 & 0.9450 & 1 \\
\hline
\end{tabular}




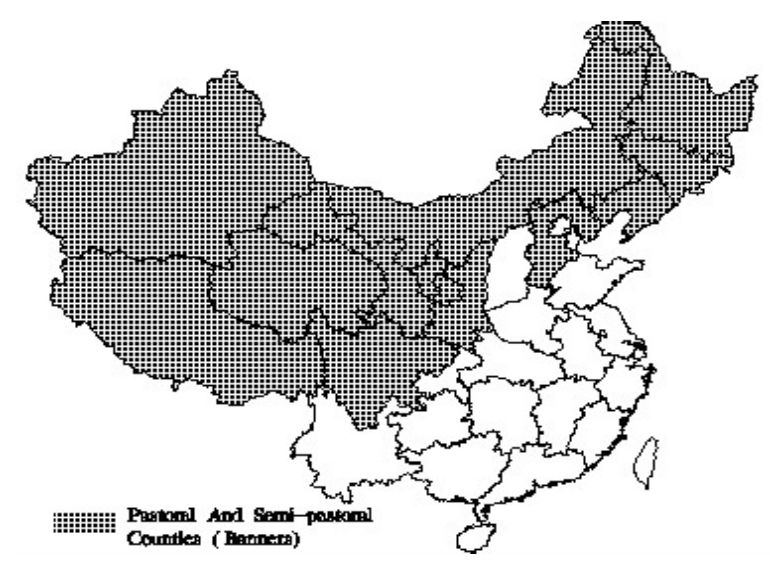

Figure 1. Pastoral and semi-pastoral counties provincial distribution in China

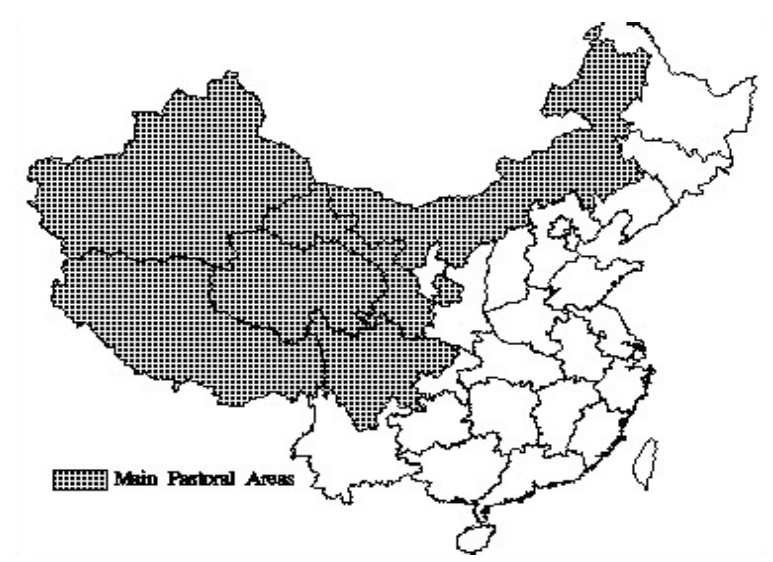

Figure 2. Distribution of main pastoral areas in (banners) China 